\title{
BMJ Open Psychological impact of injuries sustained in motor vehicle crashes: systematic review and meta-analysis
}

Ashley Craig, ${ }^{1}$ Yvonne Tran, ${ }^{1}$ Rebecca Guest, ${ }^{1}$ Bamini Gopinath, ${ }^{1}$ Jagnoor Jagnoor, ${ }^{1}$ Richard A Bryant, ${ }^{2}$ Alex Collie, ${ }^{3}$ Robyn Tate, ${ }^{1}$ Justin Kenardy, ${ }^{4}$ James W Middleton, ${ }^{1}$ lan Cameron ${ }^{1}$

To cite: Craig A, Tran Y, Guest R, et al. Psychological impact of injuries sustained in motor vehicle crashes: systematic review and metaanalysis. BMJ Open 2016;6: e011993. doi:10.1136/ bmjopen-2016-011993

- Prepublication history and additional material is available. To view please visit the journal (http://dx.doi.org/ 10.1136/bmjopen-2016011993).

Received 22 March 2016 Revised 6 July 2016 Accepted 18 August 2016

CrossMark

For numbered affiliations see end of article.

Correspondence to Professor Ashley Craig; a.craig@sydney.edu.au

\section{ABSTRACT}

Objective: The aim of this meta-analysis was to determine the psychological impact associated with motor vehicle crash (MVC)-related physical injuries.

Design: Systematic review and meta-analysis.

Data sources: Multiple search engines included MEDLINE (via OVID), PsycINF0 and Embase, and studies were sourced from scientific journals, conference papers and doctoral theses.

Study selection: A high-yield search strategy was employed. Terms like 'psychological distress', 'depression', 'PTSD' and 'motor vehicle accident' were employed. These key words were run primarily and secondary searches were then conducted in association with the major injury types. Studies needed to compare psychological distress in people injured in an MVC with uninjured controls who had not recently experienced an MVC.

Data extraction: Searches resulted in the identification of 2537 articles, and after eliminating duplicates and studies not meeting inclusion criteria, 24 studies were selected involving 4502 injured participants. These studies were entered into separate meta-analyses for mild to moderate traumatic brain injury (mTBI), whiplash-associated disorder (WAD) and spinal cord injury (SCl).

Results: Elevated psychological distress was associated with MVC-related injuries with a large summary effect size in WAD $(0.90)$, medium to large effect size in $\mathrm{SCl}(0.69)$ and small to medium effect size in $\mathrm{mTBI}(0.23)$. No studies meeting inclusion criteria were found for burns, fractures and low back injury. Increased psychological distress remains elevated in $\mathrm{SCI}, \mathrm{mTBI}$ and WAD for at least 3 years post-MVC.

Conclusions: Rehabilitation strategies are needed to minimise distress subsequent to MVC-related physical injuries and the scientific robustness of studies requires improvement.

\section{INTRODUCTION}

Injuries associated with road crashes are a primary cause of morbidity and mortality in developed and developing countries. ${ }^{1}$ The

\section{Strengths and limitations of this study}

- This is the first systematic review and meta-analysis to be conducted that evaluated and compared the psychological impact of physical injuries sustained in a motor vehicle crash.

- The meta-analysis methodology was rigorously applied and a high-yield strategy was employed to detect quality studies that investigated psychological distress associated with traumatic brain injury, spinal cord injury, whiplash, fractures, burns and back injury.

- The study also investigated the influence of time since the injury on the levels of psychological distress.

- No studies meeting inclusion criteria were found for fractures, burns or back injury.

- Variables that may moderate the psychological impact such as preinjury psychological status and compensation status were not able to be investigated as they were not reported in most studies.

WHO recognises that motor vehicle crash (MVC)-related injuries represent a major public health crisis, and worryingly, injury rates are expected to escalate globally unless road safety issues are addressed. ${ }^{1}$ The economic cost worldwide is substantial, ${ }^{2}$ and injury and death rates are increasing in developing countries. ${ }^{3}$ Rates of physical injury and disability associated with an MVC are high, ${ }^{4}$ with estimates ranging between $21 \%$ and $57 \%$ of car occupants admitted to hospital following an MVC will experience disability and/or health problems in the long term. ${ }^{5}$ Prevalence and severity of injury varies according to factors such as the type of road user or fault status. ${ }^{67}$

Severe injuries that occur in road crashes, also referred to as catastrophic injury, include severe traumatic brain injury or TBI (ie, significant impact to the head resulting in extended coma), spinal cord injury (SCI), severe and 
extensive burns to the body, amputations and blindness. ${ }^{8}$ Studies have shown that $50-60 \%$ of TBI cases are associated with an MVC, ${ }^{9}$ while up to $40 \%$ of all people with acute SCI sustain their injury as a consequence of an MVC. ${ }^{10} 11$ Non-catastrophic or less severe injuries associated with road crashes are defined as non-permanent and are usually less incapacitating. However, they can be traumatising and debilitating. ${ }^{12}$ Non-catastrophic injuries include mild to moderate TBI and musculoskeletal injuries (MI). Mild to moderate TBI and MI are prevalent following an MVC (TBI between 100 and 400 per 100000 and MI up to 330 per 100000$).{ }^{13-15}$ Less is known about mild TBI (mTBI) compared to severe TBI, as there is less physical evidence of the injury given many will not have been assessed in an emergency or outpatients setting following an MVC. ${ }^{14}$ However, it has been estimated that mTBI accounts for 70$85 \%$ of all TBI cases, and symptoms can be severe. ${ }^{14}$

Psychological distress is believed to be prevalent following an MVC. Early research concluded that 21-67\% of MVC survivors experience depressive mood, up to $47 \%$ experience elevated anxiety and driving phobia, and from $20 \%$ to $40 \%$ suffer post-traumatic stress disorder (PTSD) ${ }^{7}{ }^{16}$ Elevated rates of depressed mood and anxiety have been found in people with $\mathrm{TBI}^{17}$ and $\mathrm{SCI}^{11}{ }^{18}$ as well as high levels of pain and fatigue, leading to reduced quality of life. ${ }^{17}{ }^{19-21}$ Research has also found elevated psychological distress in people with $\mathrm{MI},{ }^{22-24}$ and when MVC-related injury results in psychological distress, medical and rehabilitation costs have been found to double. ${ }^{25}$

The focus of this review is exclusively on injuries associated with an MVC because there remains a need to clarify and quantify the psychological impact across the different types of MVC-related injuries and make comparisons using a meta-analysis methodology. This has not been performed previously and psychological distress was made the focus of this study as the impacts of MVCs are potentially serious and personally traumatising. Therefore, we report a systematic review and meta-analysis of studies that investigated psychological distress associated with an MVC in which a person sustained a catastrophic or noncatastrophic physical injury. Psychological distress was defined as an unpleasant condition that can negatively influence daily functioning, including a range of symptoms commonly believed to be troubling and disturbing, such as elevated anxiety and depressive mood. The primary aim was to determine the extent of psychological distress associated with TBI, SCI, whiplash, burns, fractures and low back injury. Secondary aims included determining the influence of time since injury on psychological distress, as well as other factors like the influence of preinjury psychological status and compensation status.

\section{METHOD}

Procedure and selection of studies

To ensure a thorough systematic review of the literature on psychological distress following an MVC-related injury, a high-yield search strategy was employed. This consisted of free text keywords that included the following: 'psychological injury', 'psychopathology', 'anxiety', 'depression', 'depressive mood', 'PTSD', 'adjustment disorder', 'acute stress disorder', 'motor vehicle accident', 'motor vehicle crash' and 'road traffic crash'. These keywords were run primarily, and secondary searches were then conducted with these words in association with TBI, SCI, whiplash, MI, fractures, burns and back injury/back pain. Multiple search engines were used, and search syntax and strategies tailored to the unique capabilities of each search engine. To ensure that no papers were missed, Medical Subject Headings (MeSH) vocabulary thesaurus was also used with MeSH fixedterm descriptors in a hierarchical structure that permitted searching at various levels of specificity.

Further, multiple search engines were used, and search syntax and strategies tailored to the unique capabilities of each search engine. ${ }^{26}$ Key terms were used in multiple electronic database searches to ensure that studies meeting meta-analysis inclusion criteria (see below) were collected. The five electronic search engines included MEDLINE (via OVID), PsycINFO, Embase, Cochrane Library databases and ISI Web of Science. Relevant studies were also sourced from scientific journals as well as conference papers and doctoral theses.

The search involved combining MVC terms with psychological distress terms, then combining this with the specific injury type (eg, whiplash). Papers not meeting inclusion criteria were removed from the review. For studies meeting inclusion criteria, relevant data were recorded into spreadsheets containing study authors, reference, statistics (eg, mean, SD or other statistic), participant numbers, male/female breakdown, age range, measures used to assess psychological distress, physical injury type and severity, duration of time since the MVC and psychological disorders (eg, depression, PTSD). To check that all possible studies were identified, the process was repeated using only the psychological distress key words and the specific physical injury. All the titles and abstracts of the articles isolated by the search engines were examined so as to select studies that met inclusion criteria for the meta-analysis. As an example, online supplementary file S1 provides the search strategy used to find relevant mTBI studies.

\section{Inclusion criteria}

Studies were selected that met the following inclusion criteria: (1) the study investigated adults (aged 18+) who have had an MVC and also provided information on participant numbers; (2) mTBI studies had to contain a majority who were injured in an MVC; (3) the SCI sample had to contain a majority who were injured in an MVC; (4) the study reported control groups, usually reported as non-injured healthy controls, community norms or trauma controls; (5) the study employed validated and reliable psychometric measures of distress (eg, content and construct validity, test-retest reliability 
and internal consistency demonstrated). Psychometric measures, and their validity and reliability, are reported in the papers shown in tables $1-3$; (6) the study presented statistics that could be converted to an effect size, including mean and SD for levels of distress for both samples, or an ANOVA/t-test probability value on a test of difference of two groups, ORs, proportions or a Pearson correlation coefficient. A number of studies conducted structured clinical interviews based on Diagnostic Statistical Manual of Mental Disorders (DSM) criteria, and reported ORs or frequencies. These were converted to effect sizes using Compute.es-R software version number: $0.2-4 ;^{27}$ (7) studies of interest were required to be published in peer-reviewed journals, conference papers or research reported in a doctoral thesis, and (8) the study was published in English. Papers meeting inclusion criteria were considered to have met satisfactory scientific quality.

\section{Meta-analysis coding and computations}

One of the authors was responsible for coding studies against inclusion criteria, and coding reliability was established by another author who independently assessed a random subset of the papers. Disagreement on coding was minimal and was resolved by evaluation of a third author. Meta-analyses were performed for TBI, SCI and whiplash-associated disorder (WAD). There were no papers that met inclusion criteria for burns, fractures or back injury, so meta-analyses were not able to be conducted for these injury types. Therefore, three meta-analyses were performed and the papers these analyses were based on are shown in tables 1-3 for TBI, SCI and WAD, respectively.

R Statistical Software is a freely distributed powerful statistical platform that enables the analysis of data in sophisticated ways. To perform the meta-analysis, the Metafor package from $\mathrm{R}$ Statistical Software was used (Viechtbauer W. Metafor: Meta-Analysis Package for R; package version 0.5-7. http://CRAN.R-project.org/ package $=$ metafor $)$. The data points used for the analysis included the first assessment reported in the studies. Where there were multiple outcomes in one study, effect sizes were averaged following recommended formulas, ${ }^{28}$ providing an individual effect size for that particular paper. This was then followed by a random effects meta-analysis, given that the data were for the most part generated by independent and diverse research groups using different methodologies, including participant selection strategies, type of control group and assessment strategies. Given this diversity, it was expected that heterogeneity will be large in the meta-analyses, that is, a larger amount of between-study variability in addition to existing within-group variability. ${ }^{28} 29$

Random effects meta-analysis estimates the mean of a distribution of the effect sizes taken from each of the studies entered in the meta-analyses. The resultant mean effect size is believed to be the best estimate of the mean of the true effect for psychological distress. Additionally, random effect meta-analysis does not discount empirical information gathered from studies with small participant numbers. The assumption is that while small $\mathrm{N}$ studies are less representative, they can still provide valid empirical data. Heterogeneity was estimated by Cochran's $Q$ and $\mathrm{I}^{2}$ statistics. ${ }^{29} \mathrm{~A}$ significant $\mathrm{Q}$ statistic rejects the null hypothesis of homogeneity. An $\mathrm{I}^{2}$ value of $0 \%$ indicates no observed heterogeneity, $25 \%$ is low, $50 \%$ is moderate and $75 \%$ indicates high heterogeneity. ${ }^{29}$ The effect size chosen to be calculated by the meta-analyses was the Hedges' g statistic, believed to provide a more precise effect estimate when smaller sample size studies are entered into the meta-analysis. ${ }^{30}$ A weighting procedure for effects was used for the random effect analysis. The effect of each study was weighted by the inverse of its variance, the variance being composed of within-study and between-study variance.

A 1-study removed analysis was conducted to evaluate the validity and sensitivity of the meta-analyses. To achieve this, a fail-safe $\mathrm{N}$ analysis was performed to test for potential presence of reporting/publication bias, often referred to as the 'file-drawer' problem. ${ }^{31}$ The 'file-drawer' problem assumes that meta-analysis studies have included in their selected studies only 5\% (0.05) of papers that show type I errors, while the remaining $95 \%$ did not attain a significant finding and remain unpublished. ${ }^{32}$ Fail-safe Ns were computed using a weighted method that assumed a null effect for all hypothetical studies that were not found. ${ }^{33}$ The overall effect size of the meta-analysis is considered valid if the fail-safe $\mathrm{N}$ to reduce the overall effect size to an insignificant level substantially exceeds the number of studies found and used in the meta-analysis. ${ }^{31}$ Low numbers of studies in meta-analyses will result in the power of asymmetry tests being too low to distinguish chance from real asymmetry; therefore, funnel plot asymmetry tests were not computed given the relatively low number of studies in the three meta-analyses. ${ }^{34}$

\section{Selection of studies}

Figure 1 summarises the study selection procedure based on PRISMA guidelines (http://www.prismastatement.org/). Employing the above-mentioned inclusion criteria, the search efforts across physical injury following an MVC (TBI, SCI, WAD, back injury, burns and fractures) resulted in the identification of 2537 articles. Adjustment for duplicate studies $(\mathrm{n}=731)$ reduced the number of studies to 1986, and after title and abstract screening, a further 1631 articles were excluded (eg, no MVC participants or a minority of participants had an MVC; unspecified MVC-related injury, non-validated measures or no data to calculate an effect size). This left 355 full-text articles that were read and assessed, with a further 297 articles excluded due to reasons such as child studies, sports-related injuries, diagnostic studies or single cohort studies, resulting in 58 articles that dealt with psychological distress following injury sustained in an MVC. However, after further analysis, of the 58, 34 


\begin{tabular}{|c|c|c|c|c|c|c|}
\hline $\begin{array}{l}\text { Author and year } \\
\text { of publication } \\
\text { Quality score }\end{array}$ & $\begin{array}{l}\text { TBI }(\mathrm{N}) \\
\text { Females } \\
\text { Mean age }\end{array}$ & $\begin{array}{l}\text { Control N } \\
\text { Females } \\
\text { Mean age }\end{array}$ & $\begin{array}{l}\text { TBI } \\
\text { Sev. }\end{array}$ & $\begin{array}{l}\text { Control type } \\
\text { Mean time since } \\
\text { MVC }\end{array}$ & $\begin{array}{l}\text { Measure or clinical } \\
\text { interview criteria }\end{array}$ & $\begin{array}{l}\text { Psychological injury or } \\
\text { symptom }\end{array}$ \\
\hline Bryant and Harvey & 38 & 38 & \multirow{3}{*}{ Mild } & \multirow{3}{*}{$\begin{array}{l}\text { Non-TBI trauma } \\
1-15 \text { days }\end{array}$} & \multirow{3}{*}{$\begin{array}{l}\text { DSM-III-R structured interview } \\
\text { State-Trait Anxiety Inventory }\end{array}$} & PTSD \\
\hline (1995) & $12(\mathrm{~F})$ & $8(F)$ & & & & State anxiety \\
\hline $3 / 5$ & 31 years & 27 years & & & & Trait anxiety \\
\hline Bryant and Harvey & 79 & 92 & \multirow[t]{4}{*}{ Mild } & \multirow{4}{*}{$\begin{array}{l}\text { General trauma } \\
6 \text { months }\end{array}$} & \multirow[t]{4}{*}{ CIDI and ASDI } & \multirow[t]{4}{*}{ PTSD } \\
\hline (1999) & $24(F)$ & $31(F)$ & & & & \\
\hline $4 / 5$ & $16-$ & $16-$ & & & & \\
\hline & 65 years & 65 years & & & & \\
\hline Levin et al (2001) & 69 & 52 & \multirow{3}{*}{$\begin{array}{l}\text { Mild to } \\
\text { moderate }\end{array}$} & \multirow{3}{*}{$\begin{array}{l}\text { General trauma } \\
3 \text { months }\end{array}$} & PTSD checklist & \multirow{3}{*}{$\begin{array}{l}\text { PTSD } \\
\text { Depression }\end{array}$} \\
\hline $4 / 5$ & $20(F)$ & $15(F)$ & & & Centre for Epidemiological & \\
\hline & 35 years & 36 years & & & Studies-Depression scale & \\
\hline Vanderploeg et al & 254 & 3214 & \multirow[t]{3}{*}{ Mild } & \multirow{3}{*}{$\begin{array}{l}\text { Healthy controls } \\
0-16 \text { years }\end{array}$} & \multirow[t]{3}{*}{ DIS III-A } & \multirow{3}{*}{$\begin{array}{l}\text { Generalised anxiety disorder } \\
\text { Depression }\end{array}$} \\
\hline (2007) & All male & All male & & & & \\
\hline $3 / 5$ & 38 years & 38 years & & & & \\
\hline Bryant et al (2009) & 425 & 532 & \multirow[t]{3}{*}{ Mild } & \multirow{3}{*}{$\begin{array}{l}\text { General trauma } \\
3 \text { months }\end{array}$} & \multirow[t]{3}{*}{ CAPS-IV and SCID } & \multirow[t]{3}{*}{ PTSD } \\
\hline $4 / 5$ & $127(F)$ & $160(F)$ & & & & \\
\hline & Adult & Adult & & & & \\
\hline Bryant et al (2010) & 377 & 555 & \multirow[t]{3}{*}{ Mild } & \multirow{3}{*}{$\begin{array}{l}\text { General trauma } \\
3-12 \text { months }\end{array}$} & \multirow[t]{3}{*}{ MINI 5.5 and CAPS-IV } & \multirow[t]{3}{*}{ PTSD } \\
\hline $4 / 5$ & $114(F)$ & $143(F)$ & & & & \\
\hline & Adult & Adult & & & & \\
\hline Ponsford et al (2011) & 90 & 80 & \multirow[t]{3}{*}{ Mild } & \multirow{3}{*}{$\begin{array}{l}\text { General trauma } \\
3 \text { months }\end{array}$} & \multirow[t]{3}{*}{ Hospital Anxiety Depression Scale } & \multirow{3}{*}{$\begin{array}{l}\text { Anxiety } \\
\text { Depression }\end{array}$} \\
\hline $4 / 5$ & $23(F)$ & $29(F)$ & & & & \\
\hline & 35 years & 35 years & & & & \\
\hline Bryant et al (2013) & 357 & 473 & \multirow[t]{2}{*}{ Mild } & General trauma & \multirow[t]{2}{*}{ MINI 5.5 and CAPS-IV } & \multirow[t]{2}{*}{ PTSD } \\
\hline $4 / 5$ & Adult & Adult & & 3-24 months & & \\
\hline $\begin{array}{l}\text { In quality score, higher } \\
\text { ASDI, Acute Stress Diso } \\
\text { Diagnostic Statistical Ma } \\
\text { SCID, Structured Clinica }\end{array}$ & $\begin{array}{l}\text { al of Mental Di } \\
\text { terview for DS }\end{array}$ & IV Disorders & ev., severity & ational Neuropsychiat & $\begin{array}{l}\text { rnational Diagnostic Interview; DIS III-A, } \\
\text { nterview; mTBI, moderate traumatic brair }\end{array}$ & $\begin{array}{l}\text { terview Schedule V.3; DSM, } \\
\text { D, post-traumatic stress disorder; }\end{array}$ \\
\hline
\end{tabular}


Table 2 Papers that met inclusion criteria that investigated psychological impact of $\mathrm{SCl}$

\begin{tabular}{|c|c|c|c|c|c|}
\hline $\begin{array}{l}\text { Author and year } \\
\text { of publication } \\
\text { Quality score }\end{array}$ & $\begin{array}{l}\mathrm{SCl}(\mathrm{N}) \\
\text { Females } \\
\text { Mean } \\
\text { age }\end{array}$ & $\begin{array}{l}\text { Control } \\
\text { (N) } \\
\text { Females } \\
\text { Mean age }\end{array}$ & $\begin{array}{l}\text { Control type } \\
\text { Mean time since } \\
\text { MVC }\end{array}$ & $\begin{array}{l}\text { Measure or clinical } \\
\text { interview criteria }\end{array}$ & $\begin{array}{l}\text { Psychological } \\
\text { injury } \\
\text { or symptom }\end{array}$ \\
\hline Hancock et al (1993) & 41 & 41 & $A B$ matched & Spielberger State-Trait Anxiety & Anxiety \\
\hline $4 / 5$ & $\begin{array}{l}7(F) \\
31 \text { years }\end{array}$ & $\begin{array}{l}7(F) \\
31 \text { years }\end{array}$ & 6 months & Beck Depression Inventory & Depression \\
\hline $\begin{array}{l}\text { Kemp and Krause } \\
\text { (1999) }\end{array}$ & $\begin{array}{l}177 \\
31(F)\end{array}$ & $\begin{array}{l}62 \\
36(F)\end{array}$ & $\begin{array}{l}A B \\
14 \text { years }\end{array}$ & $\begin{array}{l}\text { Older Adult Health and Mood } \\
\text { Questionnaire }\end{array}$ & Depression \\
\hline $3 / 5$ & 40 years & 63 years & & & \\
\hline $\begin{array}{l}\text { Chung et al (2006) } \\
3 / 5\end{array}$ & $\begin{array}{l}62 \\
19(F) \\
45 \text { years }\end{array}$ & $\begin{array}{l}54 \\
20(F)\end{array}$ & $\begin{array}{l}A B \text { matched } \\
\text { About } 2 \text { years }\end{array}$ & General Health Questionnaire & $\begin{array}{l}\text { Anxiety } \\
\text { Depression }\end{array}$ \\
\hline $\begin{array}{l}\text { Craig et al (2008) } \\
4 / 5\end{array}$ & $\begin{array}{l}33 \\
7(F) \\
41 \text { years }\end{array}$ & $\begin{array}{l}33 \\
7(F) \\
39 \text { years }\end{array}$ & $\begin{array}{l}\text { AB matched } \\
\text { About } 12 \text { years }\end{array}$ & Profile of Mood States & Depressed mood \\
\hline $\begin{array}{l}\text { Craig et al (2012) } \\
4 / 5\end{array}$ & $\begin{array}{l}41 \\
2(F) \\
47 \text { years }\end{array}$ & $\begin{array}{l}41 \\
2(F) \\
47 \text { years }\end{array}$ & $\begin{array}{l}\text { AB matched } \\
\text { About } 16 \text { years }\end{array}$ & Depression, Anxiety, Stress Scales & $\begin{array}{l}\text { Depression } \\
\text { Anxiety }\end{array}$ \\
\hline
\end{tabular}

did not meet the strict quantitative eligibility criteria and were discarded. This resulted in 24 studies that met inclusion criteria and these studies were subsequently included in the meta-analyses after independent examination by another member of the research team. Online supplementary file S2 shows the 34 papers excluded from the meta-analysis in the last stage shown in the PRISMA flow diagram in figure 1.

\section{Quality analysis of the selected studies}

The following criteria were used to determine the quality of the papers selected for the meta-analysis: (1) the study involved two groups: a majority MVC group and a control non-MVC group; (2) reliable and validated psychological distress outcome measures were used; (3) a statistical power analysis was conducted to determine optimal sample size to find differences between groups; (4) appropriate statistical analyses were conducted to determine differences between groups and (5) the study used a prospective design rather than a cross-sectional design. Each criterion was awarded 1 point, for a maximum score of 5 points, with higher scores indicative of better quality. All studies were examined and the quality analysis results for all studies are shown in tables 1-3. Quality ratings of 3 or above were considered acceptable. It should also be mentioned that no studies used a randomised design, while all studies provided a satisfactory literature review and made appropriate conclusions based on their findings.

\section{RESULTS}

Traumatic brain injury

All studies were shown to be of acceptable quality. The majority $(78 \%)$ of the mTBI participants entered into the meta-analysis were injured in an MVC. Figure 2 shows the forest plot of the TBI studies entered into the meta-analyses. Eight studies met inclusion criteria involving 1689 participants with mTBI, with comparison to 5036 controls. $^{22}{ }^{35-41}$ No studies were identified involving severe TBI. Table 1 also shows that only one study compared psychological distress to that in healthy non-MVC controls, ${ }^{37}$ with all the others making comparisons to non-TBI controls with only minor injuries. Inspection of figure 2 shows that the summary effect size was small at $0.23(95 \%$ CI 0.05 to $0.41, \mathrm{p}<0.05)$, and heterogeneity was significant and large $\left(\mathrm{Q}_{7}=42.5, \mathrm{p}<0.01\right.$, $\mathrm{I}^{2}=85.7 \%, 95 \%$ CI $66 \%$ to $97 \%$ ). Two studies found no differences in psychological distress between mTBI and non-TBI injury controls, ${ }^{22} 35$ while five studies found patients with mTBI had higher levels of psychological distress. $^{36}{ }^{38-41}$ Compared to uninjured controls, one study found mTBI resulted in substantially higher levels of psychological distress. ${ }^{37}$

Comparing an injury such as mTBI to a minor trauma injury may result in reduced or no differences in distress between groups, given one would expect psychological distress to be associated with any injury sustained under traumatic circumstances. This will lead to a possible underestimation of the psychological impact of mTBI. This assumption was supported when inspecting the effect size in the study that made comparisons to healthy non-injured controls. ${ }^{37}$ The effect size in this study was 0.52 (95\% CI 0.38 to 0.65 ), suggesting that the likely psychological impact of mTBI is significant. Furthermore, removing this study from the meta-analysis resulted in a reduced and non-significant summary effect size of 0.18 (95\% CI -0.002 to $0.37 ; \mathrm{p}=0.052)$, as well as reduced heterogeneity $\left(\mathrm{Q}_{6}=25.9, \quad \mathrm{p}<0.01\right.$, $\mathrm{I}^{2}=81.9 \%$, $95 \%$ CI $54 \%$ to $97 \%$ ). 


\begin{tabular}{|c|c|c|c|c|c|}
\hline $\begin{array}{l}\text { Author and year of publication } \\
\text { Quality score }\end{array}$ & $\begin{array}{l}\text { WAD (N) } \\
\text { Females } \\
\text { Mean age }\end{array}$ & $\begin{array}{l}\text { Control (N) } \\
\text { Females } \\
\text { Mean age }\end{array}$ & $\begin{array}{l}\text { Control type } \\
\text { Mean time since MVC }\end{array}$ & Measure & $\begin{array}{l}\text { Psychological injury } \\
\text { or symptom }\end{array}$ \\
\hline Lee et al (1993) & 32 & 15 & Minor symptoms & State-Trait Anxiety Inventory and & State anxiety \\
\hline $3 / 5$ & $\begin{array}{l}32(F) \\
35 \text { years }\end{array}$ & $\begin{array}{l}15(F) \\
34 \text { years }\end{array}$ & 18.5 months & Beck Depression Inventory & $\begin{array}{l}\text { Trait anxiety } \\
\text { Depressive mood }\end{array}$ \\
\hline Radanov et al (1996) & 21 & 21 & Recovered & Freiburg Personality Inventory & Depressed mood \\
\hline $4 / 5$ & $18-55$ years & $18-55$ years & Up to 2 years & & \\
\hline Krogstad et al (1998) & 16 & 16 & Facial pain & Symptom Checklist-90 & Anxiety \\
\hline $4 / 5$ & $12(F)$ & $12(\mathrm{~F})$ & $1-3$ years & & Depression \\
\hline & 42 years & 42 years & & & GSI \\
\hline Wallis et al (1998) & 84 & 974 & Normative data & Symptom Checklist-90 & Anxiety \\
\hline $3 / 5$ & $54(F)$ & Adults & $>3$ months & & $\begin{array}{l}\text { Depression } \\
\text { GSI }\end{array}$ \\
\hline Peebles et al (2001) & 67 & 91 & Low back pain & Symptom Checklist-90 & Anxiety \\
\hline $3 / 5$ & 40 years & 40 years & 12 months & & $\begin{array}{l}\text { Depression } \\
\text { GSI }\end{array}$ \\
\hline Blokhorst et al (2002) & 47 & 47 & Healthy matched & Symptom Checklist-90 & Anxiety \\
\hline $3 / 5$ & $29(F)$ & $29(F)$ & $>6$ months & & Depression \\
\hline & 34 years & 34 years & & & GSI \\
\hline Mayou and Bryant (2002) & 278 & 219 & Other injuries & Hospital Anxiety and Depression & Anxiety \\
\hline $4 / 5$ & $170(F)$ & $94(F)$ & 3 months -3 years & PSS scale & Depression \\
\hline & 33 years & 30 years & & & PTSD \\
\hline Wenzel et al (2002) & 1704 & 59406 & Other injuries & Hospital Anxiety and Depression & Anxiety \\
\hline $4 / 5$ & $50 \%(F)$ & $50 \%(F)$ & $>2$ years & & Depression \\
\hline & Adult & Adult & & & \\
\hline Gaab et al (2005) & 20 & 20 & Healthy matched & Hospital Anxiety and Depression & Anxiety \\
\hline $4 / 5$ & $10(F)$ & $10(F)$ & $>6$ months & & Depression \\
\hline & 36 years & 36 years & & & \\
\hline Guéz et al (2005) & 19 & 21 & Neck pain & Minnesota Multiphasic Personality Inventory-2 & Depression \\
\hline $3 / 5$ & $14(F)$ & $14(F)$ & and norms $(\mathrm{N}=500)$ & & \\
\hline & 41 years & 43 years & 6 years & & \\
\hline Hours et al (2014) & 171 & 207 & Mild injuries & PTSD Checklist Scale & PTSD \\
\hline $4 / 5$ & $107(\mathrm{~F})$ & $81(F)$ & 12 months & & \\
\hline & Adult & Adult & & & \\
\hline
\end{tabular}

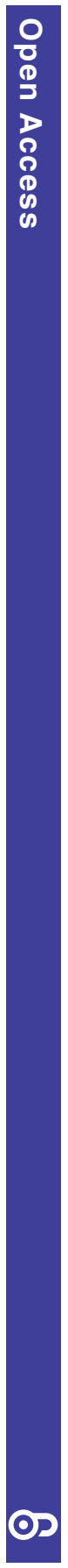

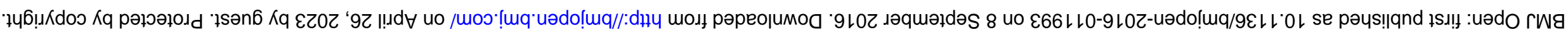


Figure 1 Flow diagram showing PRISMA selection process of the studies eligible for inclusion.

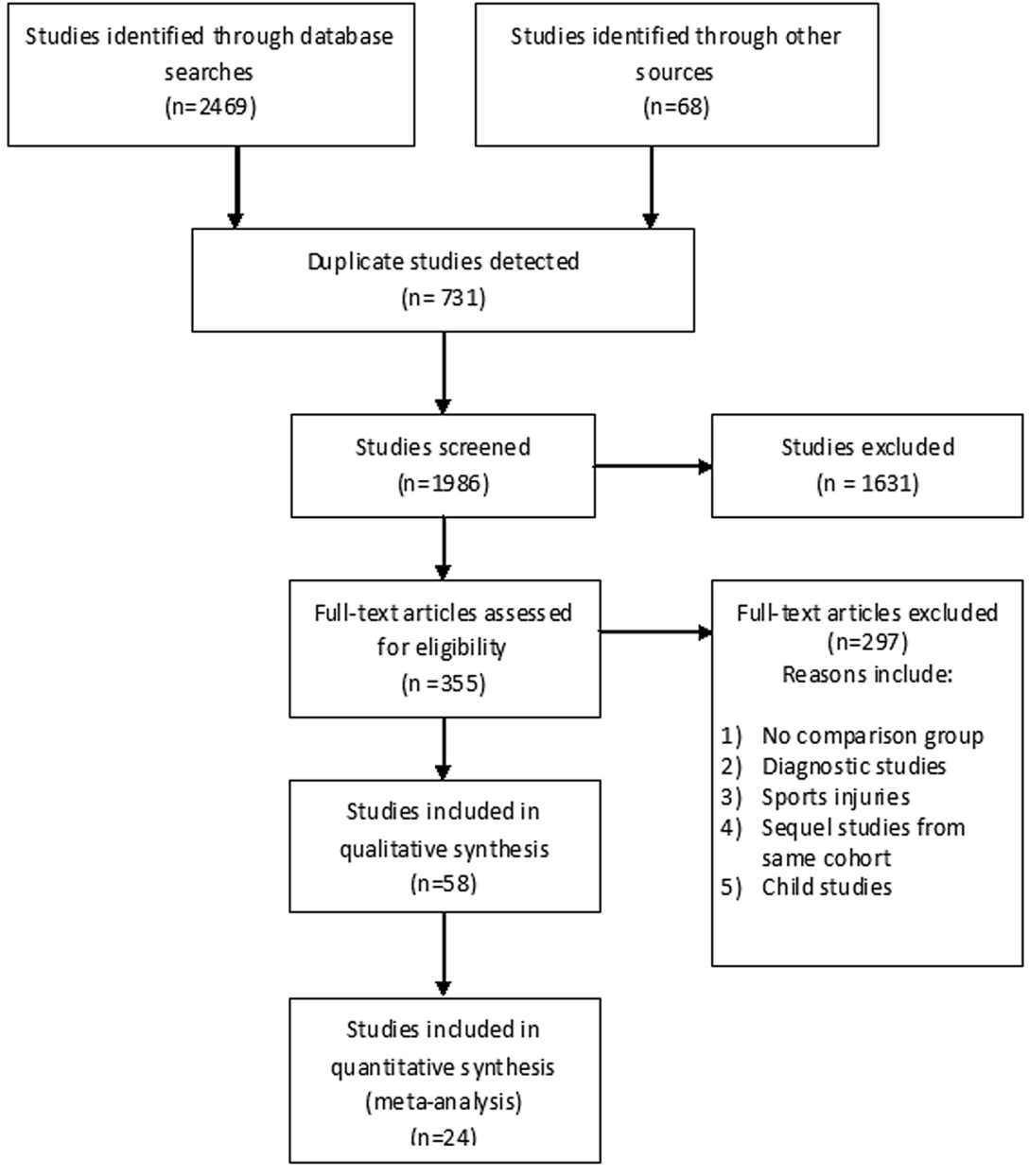

\section{Spinal cord injury}

All studies were shown to be of acceptable quality. The mean percentage of causes of SCI in the five studies was calculated, with the majority of causes resulting from trauma of which MVC was the most prevalent cause $(45 \%)$, followed by falls $(20.6 \%)$, sporting accidents $(15.5 \%)$, and less frequently due to assaults and nontraumatic causes like disease. Figure 3 shows the forest plot of the five SCI studies and table 2 provides additional detail. The five studies that met inclusion criteria involved 354 participants with SCI, with comparison to 231 able-bodied non-MVC controls. ${ }^{20}{ }^{42-45}$ Inspection of figure 3 shows that the summary effect size was moderate to large at $0.69(95 \%$ CI 0.48 to $0.89, \mathrm{p}<0.001)$, and heterogeneity was non-significant and moderate $\left(Q_{4}=8.5\right.$, $\mathrm{p}=0.07, \mathrm{I}^{2}=53.4 \%, 95 \%$ CI $0 \%$ to $\left.94 \%\right)$. All five studies found increased psychological distress in adults with SCI when compared to uninjured controls. These studies involved a mixture of participants with tetraplegia and paraplegia with either complete or incomplete lesions. Injury factors such as level of injury or completeness of the lesion were reported to have no significant influence on psychological distress. ${ }^{20} 4244$ While $45 \%$ of participants with SCI in these five studies had sustained their injury in an MVC, where data were available, further analysis showed that those injured in an MVC were not significantly different in psychological distress to participants injured in a fall, sporting accident or due to a non-traumatic cause such as disease. ${ }^{20} 45$

\section{Whiplash-associated disorder}

All studies were shown to be of acceptable quality. Figure 4 shows the forest plot of the whiplash or WAD studies. Eleven studies met inclusion criteria involving 2459 participants with WAD, with comparison to 61037 controls. ${ }^{46-56}$ Inspection of table 3 shows that three studies compared psychological impact in WAD to noninjured controls, ${ }^{45} 54$ seven studies compared WAD to a mix of general injury trauma patients such as fractures $^{46-4850525356}$ and one study made comparisons to non-whiplash neck pain and norms. ${ }^{55}$ Inspection of figure 4 shows that even including comparisons to general injury trauma patients, the summary effect size was large at $0.90(95 \%$ CI 0.45 to $1.35, \mathrm{p}<0.001)$, and heterogeneity was significant and large $\left(Q_{10}=480.2\right.$, $\mathrm{p}<0.001, \mathrm{I}^{2}=97.8 \%, 95 \%$ CI $95 \%$ to $99 \%$ ). Four studies found that participants with WAD had significantly increased levels of psychological distress to injury controls, ${ }^{46-48} 55$ while three studies found that participants with WAD had substantially higher psychological distress compared to non-injury controls. 495154 


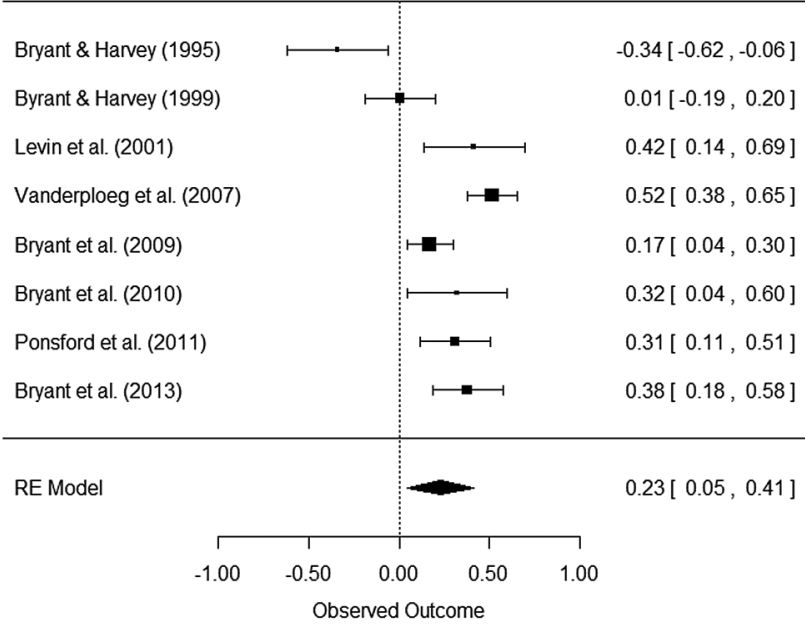

Figure 2 Meta-analysis and forest plot results for the eight mTBI studies, including Hedges' g effect sizes, 95\% Cls and the overall effect size for all eight studies. Effect sizes to the right indicate that the mTBI samples have higher levels of psychological distress. mTBI, moderate traumatic brain injury.

The summary effect size in the three studies that made comparisons to non-injured controls or norms ${ }^{49} 5154$ was very large at 1.72 (95\% CI 1.5 to 2.0 , $\mathrm{p}<0.001)$, while heterogeneity was reduced $\left(\mathrm{Q}_{2}=4.9\right.$, $\mathrm{p}=\mathrm{ns} ; \mathrm{I}^{2}=64.8 \%, 95 \%$ CI $0 \%$ to $99 \%$ ). This suggests that the negative psychological impact of a WAD injury is substantial. Removing these three studies from the meta-analyses resulted in a reduced but still significant summary effect size of 0.55 (95\% CI 0.17 to 0.93 , $\mathrm{p}<0.01)$, while heterogeneity remained high $\left(\mathrm{Q}_{7}=56.5\right.$, $\mathrm{p}<0.01 ; \mathrm{I}^{2}=95.0 \%, 95 \%$ CI $87 \%$ to $99 \%$ ).

\section{Sensitivity of the meta-analyses}

Results for the '1-study removed analysis' were found to be consistent with the original meta-analysis results when all studies were included, increasing confidence in the robustness of the meta-analyses. For the TBI analysis, the fail-safe $\mathrm{N}$ was found to be $135(\mathrm{p}<0.001)$; for the SCI analysis, it was $169(\mathrm{p}<0.001)$; and for the WAD analysis, it was $1935(\mathrm{p}<0.001)$. These estimates are substantially greater than the numbers of studies entered into the three meta-analyses, based on a $95 \%$ normal distribution calculation. Therefore, the results of the fail-safe $\mathrm{N}$ analyses suggest that the effect sizes found in the three meta-analyses are robust.

Since various psychological distress outcome measures were pooled in the meta-analyses, a series of homogenous analyses were conducted with similar measures (ie, only depressive mood measures, anxiety measures or PTSD measures) across the three injury types. These analyses confirmed the quantitative results of the meta-analyses for the three injury types. For instance, for mTBI, the depressive mood analysis revealed an effect of 0.20 (95\% CI -0.18 to 0.58 ), and for WAD, it revealed an effect of 0.99 (95\% CI 0.62 to 1.37), both of which

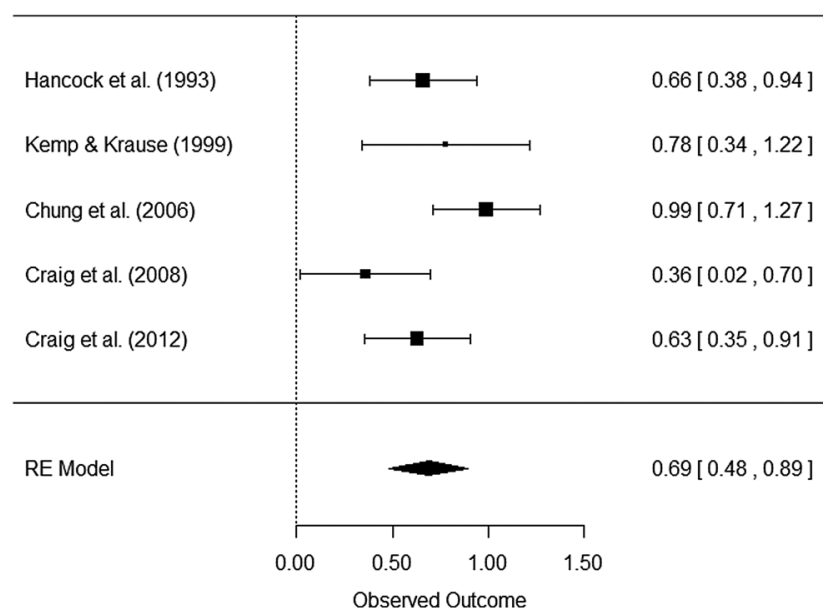

Figure 3 Meta-analysis and forest plot results for the five SCl studies, including Hedges' g effect sizes, 95\% Cls and the overall effect size for all five studies. Effect sizes to the right indicate that the $\mathrm{SCl}$ samples have higher levels of psychological distress. SCl, spinal cord injury.

are similar to the overall effect for mTBI and WAD (see figures 3 and 4, respectively). For anxiety in WAD, the homogenous analysis resulted in an effect of $0.78(95 \%$ CI 0.33 to 1.24), which is similar to the overall effect for WAD. However, a trend existed in which the effect for PTSD was lower for WAD and mTBI.

Time since injury, preinjury and compensation status, and preinjury psychological distress

All studies entered into the meta-analyses provided an indicator of the level of psychological distress (either psychometric measure or DSM ORs converted to effect sizes) as a function of time since the injury. For mTBI

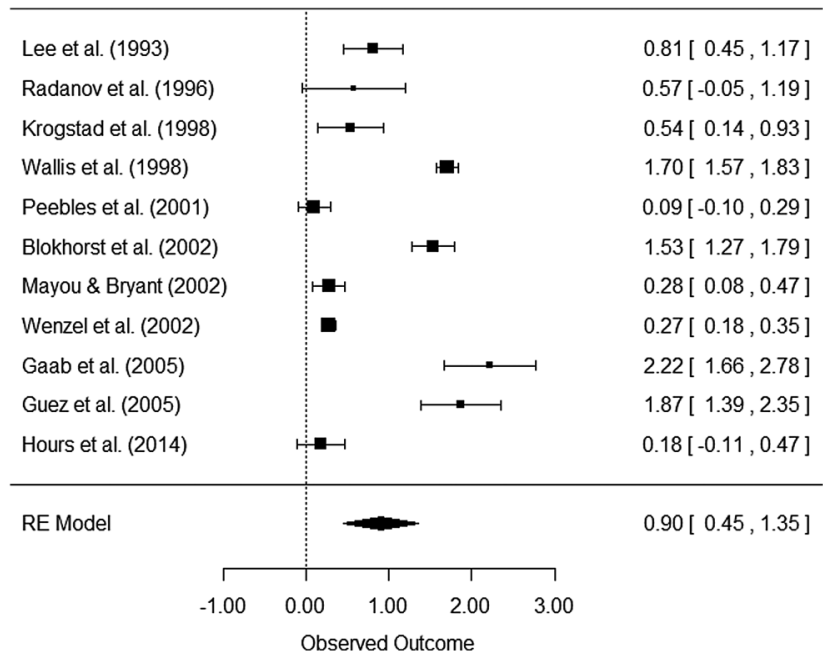

Figure 4 Meta-analysis and forest plot results for the 11 WAD studies, including Hedges' g effect sizes, 95\% Cls and the overall effect size for all 11 studies. Effect sizes to the right indicate that the WAD samples have higher levels of psychological distress. WAD, whiplash-associated disorder. 
and WAD, most studies assessed distress levels 3 months after the injury, with extended assessment from 6 to 36 months postinjury. For SCI, psychological distress was assessed from 6 to 24 months postinjury, with some extending assessment to over 10 years postinjury. The majority of mTBI and WAD studies found that psychological distress either remained stable or increased over time, while psychological distress had begun to reduce by around 10 years postinjury in the SCI studies. To assist in understanding the influence of time since injury, psychological distress effect size differences between the mTBI, WAD and SCI groups and controls were entered into a regression as a function of time since injury. Given the small number of effect sizes for each injury type, all effect sizes were included in a linear regression analysis with effect size on the vertical axis and time since injury on the horizontal axis. Inspection of figure 5 suggests that psychological distress remained elevated and stable over time $\left(\mathrm{R}^{2}=0.0003, \mathrm{p}=\mathrm{ns}\right)$. It is accepted that pooling all injury types together is a limitation of this analysis, especially given variations in time that will occur for the MVC participants as well as for the controls. The linear regression, however, does provide an estimate of the association between time since injury and the psychological distress effects. Furthermore, few studies entered into the meta-analysis provided rigorous detail of preinjury psychological status or compensation status, so the influence of these factors on psychological distress was not analysed.

\section{DISCUSSION}

Our findings reveal that psychological distress following an MVC is substantial. In three major types of injury associated with an MVC, levels of psychological distress were elevated when compared to people with no injury. Summary effect sizes were large for WAD and SCI and small to medium for people with minor to moderate TBI. It was not possible to conduct meta-analyses for less common injuries like burns, and more common injuries like fractures and low back injuries, ${ }^{57} 58$ nor was it possible to investigate the influence of compensation. ${ }^{59-65}$

The findings of this meta-analysis confirm the results of research that indicates injury and trauma experienced in an MVC can be associated with significant psychological distress. ${ }^{4} 56667$ This meta-analysis is unable to determine whether psychological distress is elevated by the injury and/or the trauma of the accident. However, one of the whiplash studies ${ }^{55}$ controlled for trauma and found that the whiplash group had significantly elevated distress. However, it is likely that psychological distress is elevated when people experience a traumatic accident even when sustaining no injury.

The causes of psychological distress observed following physical injury sustained in an MVC are multifactorial, and could include ongoing memories and flashbacks of the accident, having elevated levels of distress prior to the MVC, experiencing a protracted adversarial compensation process and financial hardship through loss of employment or delayed return to work. The findings of this meta-analysis suggest that some people injured in an MVC will develop elevated psychological distress when faced by such multiple stressors, increasing their risk of mental disorder. Strategies for assisting people to deal with these stressors could include altering compensation/legal processes to make it less distressing and adversarial, providing adequate resources for return to work and providing programmes that increase resilience. A recent meta-analysis concluded that self-help psychological interventions for people with physical illnesses are effective at lowering psychological distress, ${ }^{68}$ and these interventions could be adapted for people sustaining MVC-related injuries. An advantage of self-help approaches is that they can be delivered in diverse ways, including self-help manuals, email or web-based therapies, or fact sheets delivered by insurers or regulators, with minimal clinical professional support. ${ }^{68}$

The majority of the mTBI and the WAD studies compared psychological distress to other traumatic injuries. This is of interest if the aim is to determine whether
Figure 5 Regression of effect sizes for psychological distress following an MVC for the three MVC-related injury types. MVC, motor vehicle crash.

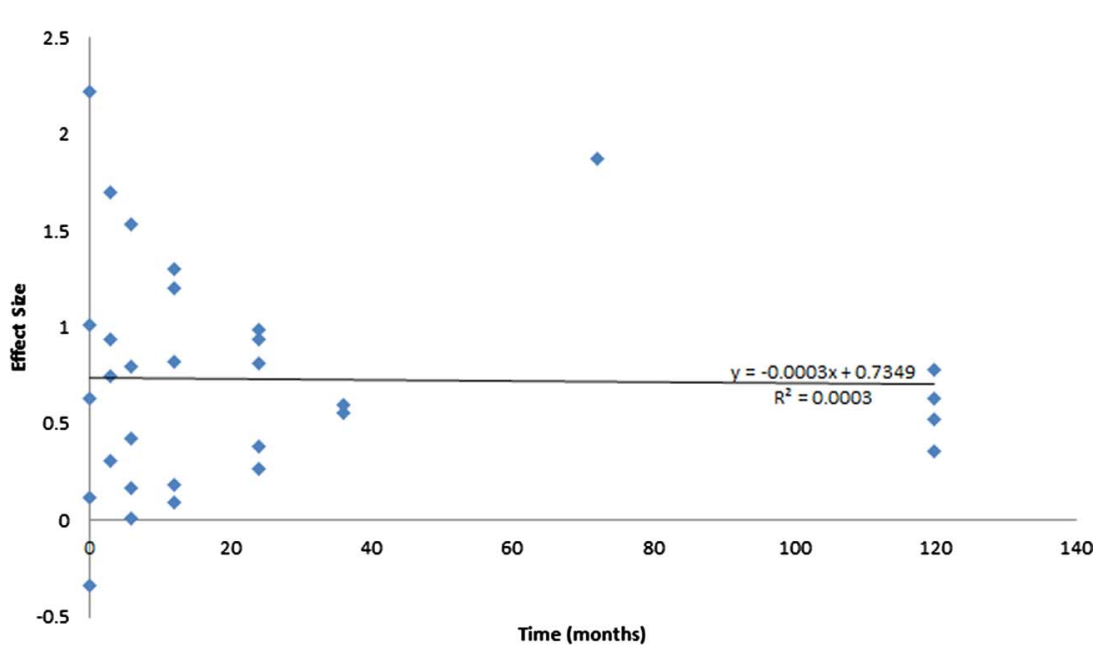


mTBI and WAD are associated with greater distress than general trauma injuries sustained in an MVC. However, such a design does not control for the psychological impact of MVC-related injury and associated trauma. Nevertheless, the findings are pertinent. For mTBI, the majority of studies found that mTBI produced increased levels of distress, while the one study that made comparisons to uninjured controls concluded that mTBI produces substantially higher risks of distress. ${ }^{37}$ Similarly, the majority of WAD studies compared psychological distress in people with a WAD to non-WAD injuries. Four of these studies found significantly increased distress levels associated with a WAD, while the three that made comparison to uninjured controls found substantially elevated levels of distress in people with WAD. It would be beneficial if future research employed uninjured controls who had not experienced an MVC, so as to strengthen our understanding of the impact of injuries like WAD and mTBI on mental health.

There are no obvious reasons why psychological distress in people with a WAD should be higher than in people with SCI or mTBI. Several explanations are possible. For instance, chronic pain increases psychological distress, and WAD sufferers can experience severe chronic pain, ${ }^{24}$ however, so do people with SCI and mTBI. ${ }^{19}{ }^{69}$ Additionally, severity of injury has rarely been found to influence psychological distress in SCI. ${ }^{20}$ A possible explanation suggests that people with a SCI receive substantial inpatient rehabilitation time compared to a WAD or mTBI, and this prolonged input may result in reduced risk of psychological distress. Also, social stigma and stereotypes (eg, alleged malingering/feigning injury symptoms for financial gain) may also increase distress in someone with a WAD, given that this injury is largely 'invisible' and WAD sufferers may be worried about what others think. WAD can result in very upsetting chronic symptomatology that when questioned (especially in a compensation or work setting) may result in frustration, anger and eventually depression. However, any differences in psychological distress between the WAD, mTBI and SCI groups may also be explained by differences in proportions of injured people in the groups and differences in outcome measures used. This area requires further research.

While the meta-analysis supports the conclusion that traumatic injury has significant psychological impact, less is known about this impact over time. The results of the regression presented in figure 5 indicate that distress, at least up to 2-3 years postinjury, remains elevated and stable. The data suggest that for many people, the psychological impact of these two injuries continues up to at least 3 years after the injury. The findings for SCI suggest that the injury has ongoing negative psychological effects even 10 years after the injury, though results may be influenced by long-term sampling bias. It is concerning that these injuries are associated with prolonged distress years after the injury, particularly since this could lead to increased occurrence of mental disorders like depression and PTSD, extend the risk of absence from work and lengthen compensation settlement times.

The psychological benefits of enhancing social support and participation are well known for post-traumatic adjustment, ${ }^{70} 71$ and interventions should integrate strategies for strengthening social support networks in people suffering an MVC. Further, effective self-management/ self-help interventions are needed that reduce risks of psychological distress following traumatic injury. Recent research attempted to reduce psychological distress following trauma-related injury using an early intervention programmes involving education, guidance on selfmanagement and information on pain management. ${ }^{72}$ However, this intervention provided no benefit in terms of psychological outcomes. Evidence from a longitudinal study suggests that post-traumatic stress interacted with the stress associated with the compensation process to predict levels of PTSD severity, ${ }^{73}$ indicating that interventions are needed that address the distress associated with MVC injury and compensation. Clearly, research is required on developing efficacious self-management interventions designed to protect against elevated psychological distress following an MVC-related injury.

\section{Study limitations}

Limitations of this meta-analysis require addressing. The low number of studies that met inclusion criteria highlights the lack of controlled research in this area. For this reason, the selection of studies that included a majority of people injured in an MVC was necessary (such as for SCI and mTBI). However, all the studies had a majority of participants injured in an MVC $(100 \%$ of WAD, $45 \%$ of SCI and $78 \%$ of MTBI participants). The low numbers of studies also limited the ability to conduct subanalyses, such as for compensation, return to work, age at the time of the injury and preinjury psychological status. Performing meta-analyses when there are varying proportions of injured participants in the samples is also a limitation. The influence of preinjury status is an important factor to control for since people who sustain traumatic injuries and develop distress tend have higher rates of psychological problems preinjury, ${ }^{74}$ predisposing these people to higher levels of distress postinjury. ${ }^{74}$ This needs to be addressed in future research, perhaps through selection of family noninjured controls. It would also be desirable to control for trauma exposure and severity in future research.

Heterogeneity was high, and perhaps a major source of this was the inclusion into the meta-analyses of injury versus uninjured controls as well as lack of methodological rigor.

Related to this source of variance is the concern about the qualities of the injury groups. In the prospective studies, for instance, their status over the course of the research will vary, given that post-traumatic stress can often diminish for a majority and so add additional heterogeneity. It should also be noted that there is 
considerable ambiguity about the operational definitions of mTBI, postconcussive syndrome and PTSD symptoms. Whereas mTBI is typically defined as documented injury to the head, loss of consciousness for $<30 \mathrm{~min}$, no focal neurological deficit and normal CT finding, ${ }^{75}$ studies included in this meta-analysis used variable definitions of mTBI. This renders comparisons difficult. Further, overlap exists between symptoms of PTSD and postconcussive syndrome, including irritability, anxiety and concentration difficulties. ${ }^{76}$ Disentangling the potential effects of mTBI (as a function of neurological insult) and the symptoms of PTSD is a perennial difficulty that makes studying the psychological effects a challenge. Another limitation involves the use of group means to calculate effect sizes in the meta-analyses. Recent research using latent class growth modelling trajectory research has produced subgroup data that demonstrate how subgroups adjust, with many coping well long-term. Prospective trajectory research will improve our understanding of how subgroups adjust following injury. ${ }^{77-79}$

\section{CONCLUSIONS}

In conclusion, trauma-related MVC injuries are associated with elevated psychological distress that can continue years after the injury. Involvement in compensation will likely add to this distress. However, more research is needed to confirm the extent of this distress, and when and how this distress becomes a mental disorder. The results of this meta-analysis reveal the need for controlled research in this area, and also have implications for health professionals such as rehabilitation medicine specialists, clinical psychologists, lawyers, compensation scheme designers and managers, and for employers involved in the ongoing treatment of MVC-related injury survivors. At very least professionals should be alert to the heightened risks of elevated psychological distress. They should also be aware that elevated levels of distress may be maintained postinjury for many years. Finally, evidence-based psychological/lifestyle strategies for preventing distress becoming chronic are required.

\section{Author affiliations \\ ${ }^{1} J o h n$ Walsh Centre for Rehabilitation Research, Kolling Institute for Medical Research, Sydney Medical School-Northern, The University of Sydney, St Leonards, New South Wales, Australia \\ ${ }^{2}$ School of Psychology, University of New South Wales, Kensington, New South Wales, Australia \\ ${ }^{3}$ Institute for Safety Compensation and Recovery Research, Monash University, Melbourne, Victoria, Australia \\ ${ }^{4}$ School of Psychology and Centre of National Research on Disability and Rehabilitation Medicine (CONROD), University of Queensland, Brisbane, Queensland, Australia}

Twitter Follow Alex Collie at @axcollie

Contributors ACr, YT and RG contributed to the study conception and design, literature screening, acquisition of data, analysis and interpretation of data, drafting of the manuscript and revision based on the comments of the coauthors. BG and JJ performed literature searching and screening and revision based on the comments of reviewers. RAB, ACo, RT, JK, JWM and IC contributed to study conception and design and revision based on the comments of reviewers. All the authors approved the submitted for publication.

Funding This research was funded by a competitive grant from the State Insurance Regulatory Authority (formerly the Motor Accident Authority NSW); MAA ref: $14 / 366$

Competing interests None declared.

Provenance and peer review Not commissioned; externally peer reviewed.

Open Access This is an Open Access article distributed in accordance with the Creative Commons Attribution Non Commercial (CC BY-NC 4.0) license, which permits others to distribute, remix, adapt, build upon this work noncommercially, and license their derivative works on different terms, provided the original work is properly cited and the use is non-commercial. See: http:// creativecommons.org/licenses/by-nc/4.0/

\section{REFERENCES}

1. Peden M, Scurfield R, Sleet D, et al. World report on road traffic injury prevention. Geneva: World Health Organization, 2004.

2. Economic Commission for Europe. Statistics of road traffic accidents in Europe and North America. Geneva: United Nations, 2011.

3. Ameratunga S, Hijar M, Norton R. Road-traffic injuries: confronting disparities to address a global-health problem. Lancet 2006;367:1533-40.

4. Harris IA, Young J, Rae H, et al. Predictors of general health after major trauma. J Trauma Inj Infect Crit Care 2008;64:969-74.

5. Ameratunga SN, Norton RN, Bennett DA, et al. Risk of disability due to car crashes: a review of the literature and methodological issues. Injury 2004;35:1116-27.

6. Littleton SM, Hughes DC, Poustie SJ, et al. The influence of fault on health in the immediate post-crash period following road traffic crashes. Injury 2012;43:1586-92.

7. Mayou R, Bryant B. Consequences of road traffic accidents for different types of road user. Injury 2003;34:197-202.

8. http://www.lifetimecare.nsw.gov.au

9. Harradine PG, Winstanley JB, Tate R, et al. Severe traumatic brain injury in New South Wales: comparable outcomes for rural and urban residents. Med J Australia 2004;181:130-4.

10. van den Berg MEL, Castellote JM, Mahillo-Fernandez I, et al. Incidence of spinal cord injury worldwide: a systematic review. Neuroepidemiology 2010;34:184-92.

11. Craig A, Nicholson Perry K, Guest R, et al. Prospective study of the occurrence of psychological disorders and comorbidities after spinal cord injury. Arch Phys Med Rehabil 2015;96:1426-34.

12. Giannoudis PV, Mehta SS, Tsiridis E. Incidence and outcome of whiplash injury after multiple trauma. Spine 2007;32:776-81.

13. Galasko CSB, Murray PA, Pitcher M. Prevalence and long-term disability following whiplash-associated disorder. J Musculoskel Pain 2000;8:15-27.

14. Khan F, Baguley IJ, Cameron ID. Rehabilitation after traumatic brain injury. Med J Aust 2003;178:290-5.

15. Cassidy JD, Boyle E, Carroll LJ. Population-based, inception cohort study of the incidence, course, and prognosis of mild traumatic brain injury after motor vehicle collisions. Arch Phys Med Rehabil 2014;95 (Suppl 2):S278-85.

16. Blaszczynski A, Gordon K, Silove D, et al. Psychiatric morbidity following motor vehicle accidents: a review of methodological issues. Comp Psychiatry 1998;39:111-21.

17. Seel RT, Kreutzer JS, Rosenthal M, et al. Depression after traumatic brain injury: a National Institute on Disability and Rehabilitation Research model systems multicenter investigation. Arch Phys Med Rehabil 2003;84:177-84.

18. Williams R, Murray A. Prevalence of depression after spinal cord injury: a meta-analysis. Arch Phys Med Rehabil 2015;96:133-40.

19. Craig A, Tran $Y$, Siddall $P$, et al. Developing a model of associations between chronic pain, depressive mood, chronic fatigue and self-efficacy in people with spinal cord injury. J Pain 2013;14:911-20.

20. Craig A, Tran $\mathrm{Y}$, Wijesuriya $\mathrm{N}$, et al. Fatigue and tiredness in people with spinal cord injury. J Psychosom Res 2012;73:205-10.

21. Wijesuriya N, Tran $\mathrm{Y}$, Middleton J, et al. Impact of fatigue on the health-related quality of life in persons with spinal cord injury. Arch Phys Med Rehabil 2012;93:319-24.

22. Bryant RA, Harvey AG. Psychological impairment following motor vehicle accidents. Aust J Publ Health 1995;19:185-8. 
23. Heron-Delaney M, Kenardy J, Charlton E, et al. A systematic review of predictors of posttraumatic stress disorder (PTSD) for adult road traffic crash survivors. Injury 2013;44:1413-22.

24. Sterling M, Kenardy J, Jull G, et al. The development of psychological changes following whiplash injury. Pain 2003;106:481-9.

25. Chan AO, Medicine M, Air TM et al. Posttraumatic stress disorder and its impact on the economic and health costs of motor vehicle accidents in South Australia. J Clin Psychiatry 2003;64:175-81.

26. Wu YP, Aylward BS, Roberts MC, et al. Searching the scientific literature: implications for quantitative and qualitative reviews. Clin Psychol Rev 2012;32:553-7.

27. Del Re AC, 2015. http://cran.r-project.org/web/packages/compute.es/

28. Borenstein M, Hedges LV, Higgins JPT, et al. Introduction to meta-analysis. West Sussex: John Wiley \& Sons, 2009.

29. Higgins JPT, Thompson SG, Deeks JJ, et al. Measuring inconsistency in meta-analyses. BMJ 2003;327:557-60.

30. Hedges LV, Olkin I. Statistical methods for meta-analysis. New York: Academic Press, 1985

31. Rosenthal R. The file drawer problem and tolerance for null results. Psychol Bull 1979;86:638-41.

32. Scargle JD. Publication bias: the "File-Drawer" problem in scientific inference. J Scientific Explor 2000;14:91-106.

33. Rosenberg MS. The file-drawer problem revisited: a general weighted method for calculating fail-safe numbers in meta-analysis. Evolution 2005:59:464-8.

34. Higgins JPT, Green S. Cochrane handbook for systematic reviews of interventions. Version 5.1.0. The Cochrane Collaboration, 2011. http://www.cochrane-handbook.org

35. Bryant RA, Harvey AG. The influence of traumatic brain injury on acute stress disorder and post-traumatic stress disorder following motor vehicle accidents. Brain Inj 1999;13:15-22.

36. Levin HS, Brown SA, Song JX, et al. Depression and posttraumatic stress disorder at three months after mild to moderate traumatic brain injury. J Clin Exp Neuropsychol 2001;23: 754-69.

37. Vanderploeg RD, Curtiss G, Luis CA, et al. Long-term morbidities following self-reported mild traumatic brain injury. J Clin Exp Neuropsychol 2007;29:585-98.

38. Bryant RA, Creamer M, O'Donnell M, et al. Posttraumatic amnesia and the nature of posttraumatic stress disorder after mild traumatic brain injury. J Int Neuropsychol Soc 2009:15:862-7.

39. Bryant RA, O'Donnell ML, Creamer M, et al. The psychiatric sequelae of traumatic injury. Am J Psychiatry 2010;167: 312-20.

40. Ponsford J, Cameron P, Fitzgerald M, et al. Long-term outcomes after uncomplicated mild traumatic brain injury: a comparison with trauma controls. J Neurotrauma 2011;28:937-46.

41. Bryant RA, O'Donnell ML, Creamer M, et al. A multisite analysis of the fluctuating course of posttraumatic stress disorder. JAMA Psychiatry 2013;70:839-46.

42. Hancock KM, Craig AR, Martin J, et al. Anxiety and depression over the first year of spinal cord injury: a longitudinal study. Paraplegia 1993;31:349-57.

43. Kemp BJ, Krause JS. Depression and life satisfaction among people ageing with post-polio and spinal cord injury. Dis Rehabil 1999;21:241-9.

44. Chung MC, Preveza E, Papandreou K, et al. The relationship between post-traumatic stress disorder following spinal cord injury and locus of control. J Affect Disord 2006;93:229-32.

45. Craig A, Tran Y, Lovas $Y$, et al. Spinal cord injury and its association with negative psychological states. Int J Psychosoc Rehabil 2008:12:115-21.

46. Lee J, Giles K, Drummond PD. Psychological disturbances and an exaggerated response to pain in patients with whiplash injury. J Psychosom Res 1993;37:105-10.

47. Radanov BP, Begré S, Sturzenegger $\mathrm{M}$, et al. Course of psychological variables in whiplash injury-a 2-year follow-up with age, gender and education pair-matched patients. Pain 1996;64:429-34.

48. Krogstad BS, Jokstad A, Dahl BL. Somatic complaints, psychologic distress, and treatment outcome in two groups of TMD patients, one previously subjected to whiplash injury. J Orofac Pain 1998;12:136-44.

49. Wallis BJ, Lord SM, Barnsley L, et al. The psychological profiles of patients with whiplash-associated headache. Cephalalgia 1998:18:101-5.

50. Peebles JE, McWilliams LA, MacLennan RA. Comparison of symptom checklist 90-revised profiles from patients with chronic pain from whiplash and patients with other musculoskeletal injuries. Spine 2001;26:766-70.
51. Blokhorst MG, Lousberg R, Vingerhoets AJ, et al. Daily hassles and stress vulnerability in patients with a whiplash-associated disorder. Int $J$ Rehabil Res 2002;25:173-9.

52. Mayou R, Bryant B. Psychiatry of whiplash neck injury. Br J Psychiatry 2002;180:441-8.

53. Wenzel HG, Haug TT, Mykletun A, et al. A population study of anxiety and depression among persons who report whiplash traumas. J Psychosom Res 2002;53:831-5.

54. Gaab J, Baumann S, Budnoik A, et al. Reduced reactivity and enhanced negative feedback sensitivity of the hypothalamuspituitary-adrenal axis in chronic whiplash-associated disorder. Pain 2005;119:219-24.

55. Guéz M, Brännström R, Nyberg L, et al. Neuropsychological functioning and MMPI-2 profiles in chronic neck pain: a comparison of whiplash and non-traumatic groups. J Clin Exp Neuropsychol 2005;27:151-63.

56. Hours M, Khati I, Charnay $P$, et al. One year after mild injury: comparison of health status and quality of life between patients with whiplash versus other injuries. J Rheumatol 2014;41:528-38.

57. Cassidy JD, Carroll LJ, Côté $P$, et al. Low back pain after traffic collisions. A population-based cohort study. Spine 2003;28: 1002-9.

58. Davydow DS, Katon WJ, Zatzick DF. Psychiatric morbidity and functional impairments in survivors of burns, traumatic injuries, and ICU stays for other critical illnesses: a review of the literature. Int Rev Psychiatry 2009;21:531-8.

59. Elbers NA, Akkermans AJ, Lockwood K, et al. Factors that challenge health for people involved in the compensation process following a motor vehicle crash: a longitudinal study. BMC Public Health 2015; 15:339.

60. Elbers NA, Hulst L, Cuijpers $P$, et al. Do compensation processes impair mental health? A meta-analysis. Injury 2013;44: 674-83.

61. Grant GM, O'Donnell ML, Spittal MJ, et al. Relationship between stressfulness of claiming for injury compensation and long-term recovery: a prospective cohort study. JAMA Psychiatry 2014:71:446-53.

62. Murgatroyd DF, Casey PP, Cameron ID, et al. The effect of financial compensation on health outcomes following musculoskeletal injury: systematic review. PLoS ONE 2015;10:e0117597.

63. Spearing NM, Connelly LB. Is compensation "bad for health"? A systematic meta-review. Injury 2011:42:15-24.

64. Spearing NM, Connelly LB, Gargett S, et al. Does injury compensation lead to worse health after whiplash? A systematic review. Pain 2012;153:1274-82.

65. O'Donnell ML, Creamer MC, McFarlane AC, et al. Does access to compensation have an impact on recovery outcomes after injury? Med J Australia 2010;192:328-33.

66. Peden M, McGee K, Krug E. Injury: a leading cause of the global burden of disease, 2000. Geneva: WHO, 2002.

67. Blanchard EB, Hickling EJ, Taylor AE, et al. Psychiatric morbidity associated with motor vehicle accidents. J Nerv Ment Dis 1995; 183:495-504.

68. Matcham F, Rayner L, Hutton J, et al. Self-help interventions for symptoms of depression, anxiety and psychological distress in patients with physical illnesses: a systematic review and meta-analysis. Clin Psychol Rev 2014;34:141-57.

69. Lahz S, Bryant RA. Incidence of chronic pain following traumatic brain injury. Arch Phys Med Rehabil 1996;77:889-91.

70. Arnberg FK, Hultman CM, Michel PO, et al. Fifteen years after a ferry disaster: clinical interviews and survivors' self-assessment of their experience. Eur J Psychotraumatol 2013;4:20650.

71. Craig A, Nicholson Perry K, Guest R, et al. Adjustment following chronic spinal cord injury: determining factors that contribute to social participation. Br J Health Psychol 2015;20:807-23.

72. Elbers NA, Akkermans AJ, Cuijpers $P$, et al. Effectiveness of a web-based intervention for injured claimants: a randomized controlled trial. Trials 2013;14:227.

73. O'Donnell ML, Grant G, Alkemade N, et al. Compensation seeking and disability after injury: The role of compensation-related stress and mental health. J Clin Psychiatry 2015;76:e1000-5.

74. Gould KR, Ponsford JL, Johnston L, et al. The nature, frequency and course of psychiatric disorders in the first year after traumatic brain injury: a prospective study. Psychol Med 2011;41:2099-109.

75. Carroll LJ, Cassidy JD, Peloso PM, et al. Prognosis for mild traumatic brain injury: results of the WHO Collaborating Centre Task Force on mild traumatic brain injury. $J$ Rehabil Med 2004;(Suppl 43):84-105.

76. Bryant RA. Posttraumatic stress disorder and traumatic brain injury: can they co-exist? Clin Psychol Rev 2001;21:931-45. 
77. Bonanno GA, Kennedy P, Galatzer-Levy IR, et al. Trajectories of resilience, depression, and anxiety following spinal cord injury. Rehabil Psychol 2012;57:236-47.

78. Guest R, Craig A, Nicholson Perry K, et al. Resilience following spinal cord injury: a prospective controlled study investigating the influence of the provision of group cognitive behavior therapy during inpatient rehabilitation. Rehabil Psychol 2015;60:311-21.

79. Craig A, Hancock K, Chang E, et al. The effectiveness of group psychological intervention in enhancing perceptions of control following spinal cord injury. Austral N Z J Psychiatry 1998;32:112-18. 